Long-term mediational processes

\title{
in short-term memory*
}

\author{
WILLIAM M. PETRUSIC† \\ Carleton University, Ottawa, Ontario, Canada \\ and \\ BRUCE HINDS \\ University of British Columbia, Vancouver, British Columbia, Canada
}

A general paradigm for studying the interplay between STM processing under conditions of divided attention and recently acquired cognitive structures is presented. The paradigm requires the acquisition of an $n$-tuple by the usual serial anticipation method. Subsequently, selected subspan subsets of these items or synonyms or homophones of the corresponding (position for position) serially ordered items are presented for ordered recall in the Brown-Peterson paradigm. Two preliminary experiments are presented. Both demonstrate mediated facilitation of STM processing. The degree of facilitation depends on such LTM variables as the direction of associations of adjacent items and the location of the items in the long-term serial order, as well as the similarity of the items in STM to those in corresponding LTM positions. The role of item availability in assessing mediated facilitation of order information is discussed.

The interplay between STM and L T M is receiving increasing experimental study. For examples of such work in various paradigms, see Adams (1967), Adams, Thorsheim, and McIntyre (1969), Buschke and Lenon (1969), Craik and Levy (1970), Gerver (1969), and Mosher (1969).

The notion we consider in this paper is an extension of Norman's (1968) view that STM storage involves activation of units in a common storage system. Specifically, we investigate the selective preactivation of LTM units such that STM processing in the Brown-Peterson paradigm (BP) is selectively facilitated and possibly interfered with. This report is primarily concerned with developing a general paradigm to study the interplay between recently acquired cognitive structures and performance over very short retention intervals (less than $30 \mathrm{sec}$ ) under conditions of divided attention. Results from two preliminary experiments are presented.

The general paradigm requires the acquisition at time $T$ of the $n$-tuple $\left(I_{1}, I_{2}, \cdots, I_{i}, \cdots, I_{n}\right)$ by the usual long-term serial order (LT-SO) methods. At time $\mathrm{T}+t$ subsets of the items in the LT-SO are presented for serial order recall in the (BP) paradigm. The items for $B P$ recall can vary in their location and order in the

*This research was supported by grants from the National Research Council of Canada (APA-0238) and the Medical Research Council (MA-4193). The advice and assistance of Marc Barnes, Carl Boast, Allan Clarke, Bruce Connolly, and Patricia Woodland is much appreciated.

tRequests for reprints should be sent to William M. Petrusic, Department of Psychology, Carleton University, Ottawa, Ontario, Canada.
LT-SO as well as their similarity (synonyms or homophones) to the original $I_{i} s$. Varying the number of LT-SO acquisition trials and the time $t$ till testing in the BPP provides information concerning the influence of long-term associative processes on STM processing. Varying such STM variables as length of retention interval, rate of presentation, instructions to forget, and degree of capacity utilization of the rehearsal disruption task, provides information concerning the basis of LTM structures and how they exert their influence on STM processing in the BPP.

\section{Procedure}

\section{EXPERIMENT 1}

Ss in the experimental condition first learned the serial order of 16 consonants to a criterion of two errorless trials. Following the acquisition of the LT-SO, 20 items were tested for recall in BPP. Items were presented for $2 \mathrm{sec}$, then a number was presented, and $S$ counted backward by threes from that number in time to a metronome paced at $1 /$ sec. After $15 \mathrm{sec}$ of interpolated counting, a question mark appeared on the screen indicating that $\mathrm{S}$ was to output the items in the order presented. Ss in the control condition (C) were treated as above, except that instead of receiving LTM serial order training, they were presented the 16 consonants seven times, in random order, and were required to read each word aloud. This condition presumably guaranteed that, with respect to recognition, both groups were approximately equivalent. The number of trials to criterion varied from 4 to 8 in the two $E$ groups. All Ss were run individuallly.
Stimulus Materials

The LT-SO employed was FPYKMGTWRBXCJSZQ. All 20 items tested in STM were composed of letters that were in adjacent positions in the LT-SO. Ten forward (F) items were formed, e.g., FPYK TWRB, and were in the same order (visually, top to bottom of slide) as in the LT.SO. Ten backward (B) items differed only in that their order was quad for quad the reverse of the $F$ items, e.g., BRWT CXBR. The items were selected so that the LT serial position range was equally represented. This LT-SO position was approximately balanced with respect to order of presentation, e.g., in the first three trials items appearing in the middle, early, and late positions of the LT-SO list were presented. The same order of items was employed for all Ss. Separate constrained randomizations of orders were generated for $\mathrm{F}$ and $\mathrm{B}$ items.

\section{Design}

There were two experimental conditions: direction of LTM associations and order of testing $\mathrm{F}$ and $B$ blocks of items. The second condition was designed to investigate whether or not units in STM, if transferred into LTM, would selectively modify the LT-SO. Consequently, performance on subsequent BP trials would be selectively impaired and/or facilitated. Specifically, testing B items prior to testing $\mathrm{F}$ items should lead to impaired performance for $\mathrm{F}$ items tested last and presumably no difference on $B$ items if BP trials do not increment strength of the LT-SO. It should also be noted that such investigations of order effects generally can be applied to a variety of other conjectures concerning LTM structure and ST processes and their separation. Direction of associations may not be a very potent variable, although relevant. For example, proximity and higher order organizational structures may exert considerable control over processing under conditions of limited available capacity.

In Condition $\mathrm{E}_{1}, 10 \mathrm{Ss}$ recalled the $10 \mathrm{~F}$ items first, while in $\mathrm{E}_{2} 20 \mathrm{Ss}$ recalled the $B$ items first. Order was a between-S variable, while direction was within. A third group (C) of $10 \mathrm{Ss}$ served as a control to provide a baseline when recognition preactivation, but not necessarily availability, was controlled. For example, interference of forward associations on $\mathbf{B}$ items might lead to significantly poorer performance for $\mathrm{E}$ than for C Ss. Five control Ss were tested in the FB order, while the other five were tested under the BF order. 


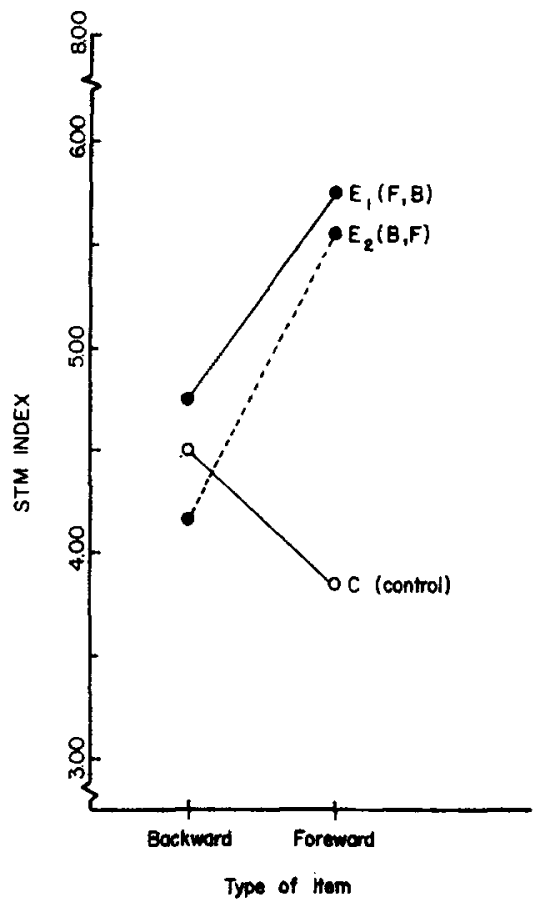

Fig. 1. STM performance as a function of type of item (Forward or Backward).

\section{Apparatus}

All items were presented by a Carousel slide projector. Durations were controlled by a Lafayette VIII bank timer.

\section{Subjects}

Forty University of British Columbia undergraduates served as unpaid volunteers.

\section{Results and Discussion}

Figure 1 presents the STM performance for each condition for the $F$ and $B$ items.

STM performance was measured by assigning a value of 2 to each item recalled in correct serial position, a value of 1 to each item correctly recalled in an incorrect serial position. Thus, the measure investigates effects of LT-SO on the STM measure employed by several Es. It should be pointed out, however, that both availability and position were influenced by LT-SO. Relative to this C group, availability was not influenced as much as was order. It appears that mediated order information acts directly upon availability of items in STM as well as on position.

A priori comparisons on the difference between the $E_{1}$ and $E_{2}$ groups were not significant. The difference between $\mathrm{C}$ and the average of the two $E$ groups, however, was reliable $[F(1,37)=6.16, p<.01]$.

The overall effect of direction was not significant, but the interaction

List of Triples (in Serial Order) Employed in the Synonym, LTM, and Homophone Conditions. Thorndike-Lorge frequencies of usage given under $f$.

\begin{tabular}{|c|c|c|c|c|c|c|c|}
\hline \multirow{2}{*}{$\frac{\text { Triple }}{1}$} & \multirow{2}{*}{$\begin{array}{c}\begin{array}{c}\text { Serial } \\
\text { Position }\end{array} \\
1 \\
2 \\
3\end{array}$} & \multicolumn{2}{|c|}{ Synony $m_{f}$} & \multicolumn{2}{|c|}{ LTM List Identical } & \multicolumn{2}{|c|}{ Homophonesf } \\
\hline & & $\begin{array}{l}\text { gain } \\
\text { correct } \\
\text { glue }\end{array}$ & $\begin{array}{l}\mathbf{A A} \\
\mathbf{A} \\
\mathbf{2 1}\end{array}$ & $\begin{array}{l}\text { protit } \\
\text { right } \\
\text { paste }\end{array}$ & $\begin{array}{l}\mathbf{A} \\
\mathbf{A A} \\
17\end{array}$ & $\begin{array}{l}\text { prophet } \\
\text { write } \\
\text { paced }\end{array}$ & $\begin{array}{l}\text { A } \\
\text { AA } \\
10\end{array}$ \\
\hline 2 & $\begin{array}{l}4 \\
5 \\
6\end{array}$ & $\begin{array}{l}\text { rule } \\
\text { highway } \\
\text { select }\end{array}$ & $\begin{array}{l}\text { AA } \\
\mathbf{3 4} \\
\mathbf{A}\end{array}$ & $\begin{array}{l}\text { reign } \\
\text { road } \\
\text { choose }\end{array}$ & $\begin{array}{l}49 \\
\mathrm{AA} \\
\mathrm{A}\end{array}$ & $\begin{array}{l}\text { rain } \\
\text { rode } \\
\text { chews }\end{array}$ & $\begin{array}{l}\mathbf{A A} \\
\mathbf{A} \\
\mathbf{1 4}\end{array}$ \\
\hline $\mathbf{3}$ & $\begin{array}{l}7 \\
8 \\
9\end{array}$ & $\begin{array}{l}\text { man } \\
\text { observe } \\
\text { vision }\end{array}$ & $\begin{array}{l}\text { AA } \\
\text { A } \\
\mathbf{4 5}\end{array}$ & $\begin{array}{l}\text { male } \\
\text { see } \\
\text { sight }\end{array}$ & $\begin{array}{l}\mathbf{3 4} \\
\mathbf{A A} \\
\mathbf{A A}\end{array}$ & $\begin{array}{l}\text { mail } \\
\text { sea } \\
\text { site }\end{array}$ & $\begin{array}{l}\mathbf{A} \\
\mathbf{A A} \\
\mathbf{2 1}\end{array}$ \\
\hline 4 & $\begin{array}{l}10 \\
11 \\
12\end{array}$ & $\begin{array}{l}\text { simple } \\
\text { odour } \\
\text { couple }\end{array}$ & $\begin{array}{l}\mathbf{A A} \\
27 \\
\mathbf{A}\end{array}$ & $\begin{array}{l}\text { plain } \\
\text { scent } \\
\text { pair }\end{array}$ & $\begin{array}{l}\text { AA } \\
24 \\
\text { AA }\end{array}$ & $\begin{array}{l}\text { plane } \\
\text { cent } \\
\text { pear }\end{array}$ & $\begin{array}{l}\mathbf{A} \\
\mathbf{A A} \\
\mathbf{2 1}\end{array}$ \\
\hline 5 & $\begin{array}{l}13 \\
14 \\
15\end{array}$ & $\begin{array}{l}\text { listen } \\
\text { pig } \\
\text { alley }\end{array}$ & $\begin{array}{l}\text { AA } \\
44 \\
13\end{array}$ & $\begin{array}{l}\text { hear } \\
\text { boar } \\
\text { lane }\end{array}$ & $\begin{array}{l}\text { AA } \\
11 \\
\mathbf{3 2}\end{array}$ & $\begin{array}{l}\text { here } \\
\text { bore } \\
\text { lain }\end{array}$ & $\begin{array}{l}\mathbf{A A} \\
\mathbf{A} \\
\mathbf{0}\end{array}$ \\
\hline 6 & $\begin{array}{l}16 \\
17 \\
18\end{array}$ & $\begin{array}{l}\text { cry } \\
\text { frog } \\
\text { rob }\end{array}$ & $\begin{array}{l}\text { A A } \\
25 \\
41\end{array}$ & $\begin{array}{l}\text { bawl } \\
\text { toad } \\
\text { steal }\end{array}$ & $\begin{array}{l}6 \\
15 \\
A\end{array}$ & $\begin{array}{l}\text { ball } \\
\text { towed } \\
\text { steel }\end{array}$ & $\begin{array}{l}\mathbf{A A} \\
\mathbf{9} \\
\mathbf{A}\end{array}$ \\
\hline
\end{tabular}

between direction and groups was $[F(2,37)=5.56, p<.01]$. Facilitation occurs, apparently, only for the $\mathrm{F}$ items.

The items tested for STM did not differ in terms of their LT serial position, nor was a clear-cut decrement over trials observed for the E group. No definite statements can be made since these two effects were confounded. Performance on the LTM list was not influenced by the STM trials. All Ss could output the original LT-SO errorlessly upon instructions to do so. Whether or not interitem associations formed during the BP trials interact with those in LTM requires further data, where number of LT-SO acquisition trials and time till testing in STM are systematically varied.

\section{EXPERIMENT 2}

Design and Stimulus Materials

The type of items in STM were identical (I), synonyms (S), or homophones $(\mathrm{H})$ of items (position for position) of items in the LT-SO. The lists of triples employed and their Thorndike-Lorge (1944) frequencies of usage are provided in Table 1. Type of item was a between-S variable and, as in Experiment 1, direction was a within-S variable. The serial position of the triad in the LT-SO and its order of presentation were Latinized over the six Ss in each condition in the same way. However, in each condition, three $S$ s received the $F$ items first and the remaining three $\mathrm{Ss}$ received the $B$ items first. The same Latinizations were utilized for both directions of the six Ss in each group. A fourth group (C) of Ss was presented the items in random order for seven trials; they articulated each item as it was presented and were tested on the I items. The obvious $S$ and $H$ control groups were not run.

\section{Procedure}

The procedure was identical to that of Experiment 1, except for (1) the $t y p e$ of interpolated rehearsal-preventing task which was digit classification (high-low and odd-even), and (2) duration of presentation, which was reduced to $1.5 \mathrm{sec}$.

\section{Subjects}

Twenty-four University of British Columbia male undergraduates served as unpaid volunteers, with $10 \mathrm{Ss}$ in each of the above groups.

\section{Results}

Figure 2 presents the mean STM performance for each type of item for the $F$ and $B$ directions. Conditions d if fered significant ly $[F(3,20)=17.06, p<.001]$, as did direction $[F(1,20)=4.59, p<.05]$. On the basis of Dunnett post hoc tests for both $F$ and $B$ items, the $I$ and $S$ conditions differ significantly from the $C$ condition, while the $\mathrm{H}$ items do not. However, it appears that the acoustic code is still available to some degree up to $15 \mathrm{sec}$. The semantic and acoustic codes are both available in LTM, and the semantic code appears to be a more efficient mediational code in STM. However, relevant control groups are necessary, and the retention interval must be varied along with utilization of a free-recall LT control condition for item availability before definite statements can be made.

No clear-cut decrement over trials was observed for either control or experimental Ss. Intrusions from the LT-SO, in appropriate STM items 


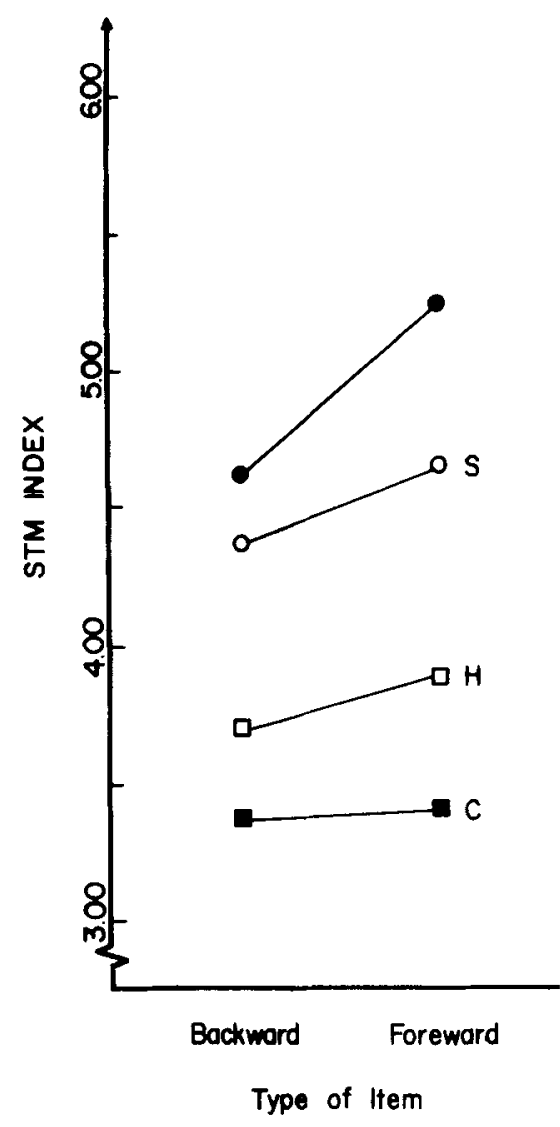

Fig. 2. STM performance as a function of type of item for the I, S, $\mathrm{H}$, and $\mathrm{C}$ groups.

(mediated) occurred for the $\mathrm{H}$ group, but only rarely for the $S$ group. If these intrusions are scored as correct, the $\mathrm{H}$ group performance approaches that of the $S$ group.

The curves for relative facilitation of STM performance as a function of the location in the LT-SO are presented in Fig. 3 for what they are worth. These curves were obtained by subtracting the mean STM performance for the $I, S$, and $H$ conditions for the $F$ and $B$ items from the BP performance on corresponding items in the $\mathrm{C}$ group. Since the overall curve was somewhat irregular, the resulting differences were averaged over adjacent positions, i.e., 1 and 2, 3 and 4 , and 5 and 6 .

The STM performance curves look like traditional LTM serial position

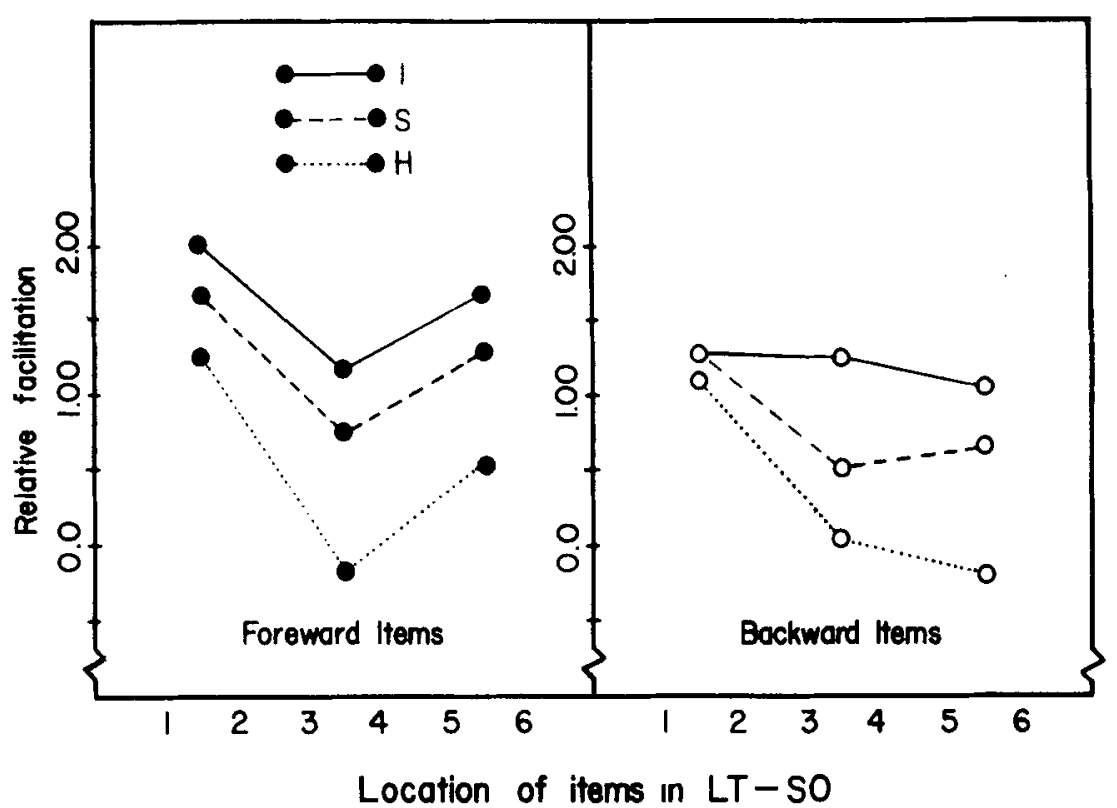

Fig. 3. Relative facilitation of STM as a function of location in the long-term serial order for forward and backward items for the I, S, and $H$ triads.

curves with a predominant primacy portion. The $B$ curves, however, in relation to the $F$ curves suggest that the list is organized primarily about the first item(s) in the LT-SO. Moreover, it would appear that backward associations decrease monotonically in strength with distance away from the structural organizational point. Further, the acoustic and semantic codes are both available for the items early in the LT-SO. These conclusions, however, are merely suggestive and need further investigation.

\section{CONCLUSIONS}

Although the influences of LT-SO structures on processing in the BP paradigm were demonstrated in this paradigm, the locus and details of how LT cognitive structures control short-term processing still remain to be explored. Information from the paradigm presented will provide answers to such questions. Further, code availability and matching now come under scrutiny, not only in the context of interference paradigms, but in terms of mediated facilitation of ST processing under limited (and varying) available capacity. Finally, continued investigation of the consequences of performance in STM tasks on LT cognitive structures will decide whether or not items are "transferred" from STM into LTM.

\section{REFERENCES}

ADAMS, J. A. Human memory, New York: McGraw-Hill, 1967.

ADAMS, J. A., THORSHEIM, H. I., \& MCINTYRE, J. S. Item length, acoustic similarity and natural language mediation as variables in short-term memory. Journal of Experimental Psychology, 1969, 80, 39-46.

BUSCHKE, M., \& LENON, R. Perceptual identification and encoding. Perception \& Psychophysics, 1969, 5, 338-340.

CRAIK, F. I. M., \& LEVY, B. A. Semantic and acoustic information in primary memory. Journal of Experimental Psychology, 1970, 86, 77-82.

GERVER, D. Effects of grammaticalness. presentation rate, and message length on auditory short-term memory. Quarterly Journal of Experimental Psychology, 1969, 21, 203-208.

MOSHER, $D$. L. The interfering effect of serial cognitive structures in long-term memory on word-order in short-term memory. Psy chonomic Science, 1969, 16, 317-318.

NORMAN, D. A. Toward a theory of memory and attention. Psychological Review, 1968, 75, 522-536.

THORNDIKE, E. L., \& LORGE, I. The teacher's word book of 30000 words. New York: Bureau of Publications, Teachers College, Columbia University, 1944 